\title{
Comprehensive experimental study on prevention of land subsidence caused by dewatering in deep foundation pit with hanging waterproof curtain
}

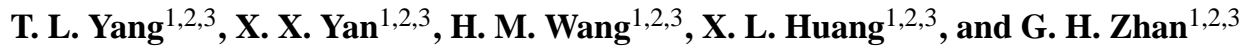 \\ ${ }^{1}$ Shanghai Institute of Geological Survey, Shanghai, 200072, China \\ ${ }^{2}$ Key Laboratory of Land Subsidence Monitoring and Prevention,Ministry of Land and Resources, \\ Shanghai, 200072, China \\ ${ }^{3}$ Shanghai Engineering Research Center of Land Subsidence, Shanghai, 200072, China \\ Correspondence to: T. L. Yang (sigs_ytl@163.com)
}

Published: 12 November 2015

\begin{abstract}
Land subsidence caused by dewatering of deep foundations pit has currently become the focus of prevention and control of land subsidence in Shanghai. Because of the reliance on deep foundation dewatering pit projects, two comprehensive test sites were established to help prevent land subsidence. Through geological environmental monitoring during dewatering of a deep foundation pit, the analysis of the relation between artesian water level and soil subsidence, some basic features of land subsidence caused by dewatering of deep foundation pits are elucidated. The results provide a scientific basis for prevention and control of land subsidence caused by dewatering in deep foundation pits.
\end{abstract}

\section{Introduction}

The exploitation and utilization of the shallow subsurface in Shanghai keeps increasing with the demands of urban development deep foundation pits used in construction, leads to a series of environmental and geological problems (Yang and Gong, 2010; Wei et al., 2009). Among the problems, the most serious is the uneven subsidence caused by the compression of shallow strata, which arises from the dewatering of deep foundation pit engineering (Yang, 2010). Research on existing foundation pit engineering reveals that dewatering during excavation for the engineered hanging waterproof curtain has a great impact on the artesian water level at significant distances from the foundation pit (Yang et al., 2009). The large decline of artesian water level beyond the foundation pit leads directly to the uneven subsidence, which adversely affects the environment and important nearby structures. Furthermore, the subsidence is difficult to regulate and threatens the elevation safety in Shanghai (Yang et al., 2014).

Taking deep foundation pits of two construction projects in Shanghai as typical cases, we conducted a comprehensive dewatering-recharge test for prevention of land subsidence during the period of excavation and dewatering. The results can be applied elsewhere to prevent and manage subsidence caused by deep foundation pit engineering.

\section{The testing design}

\subsection{Geological conditions of the testing field}

The shallow strata of the testing field, which are comprised of clay, silt and sandy soil, are normal sedimentary strata. The objective of the foundation pit engineering is to decompress the first confined aquifer (the 7th soil layer). It is characterized by large depth, high water yield and permeability. According to the foundation pit retaining design, dewatering for decompression during the excavation is necessary. The underground continuous wall as a hanging waterproof curtain did not block the target aquifer - thus there is a directly hydraulic connection inside and outside the foundation pit. 


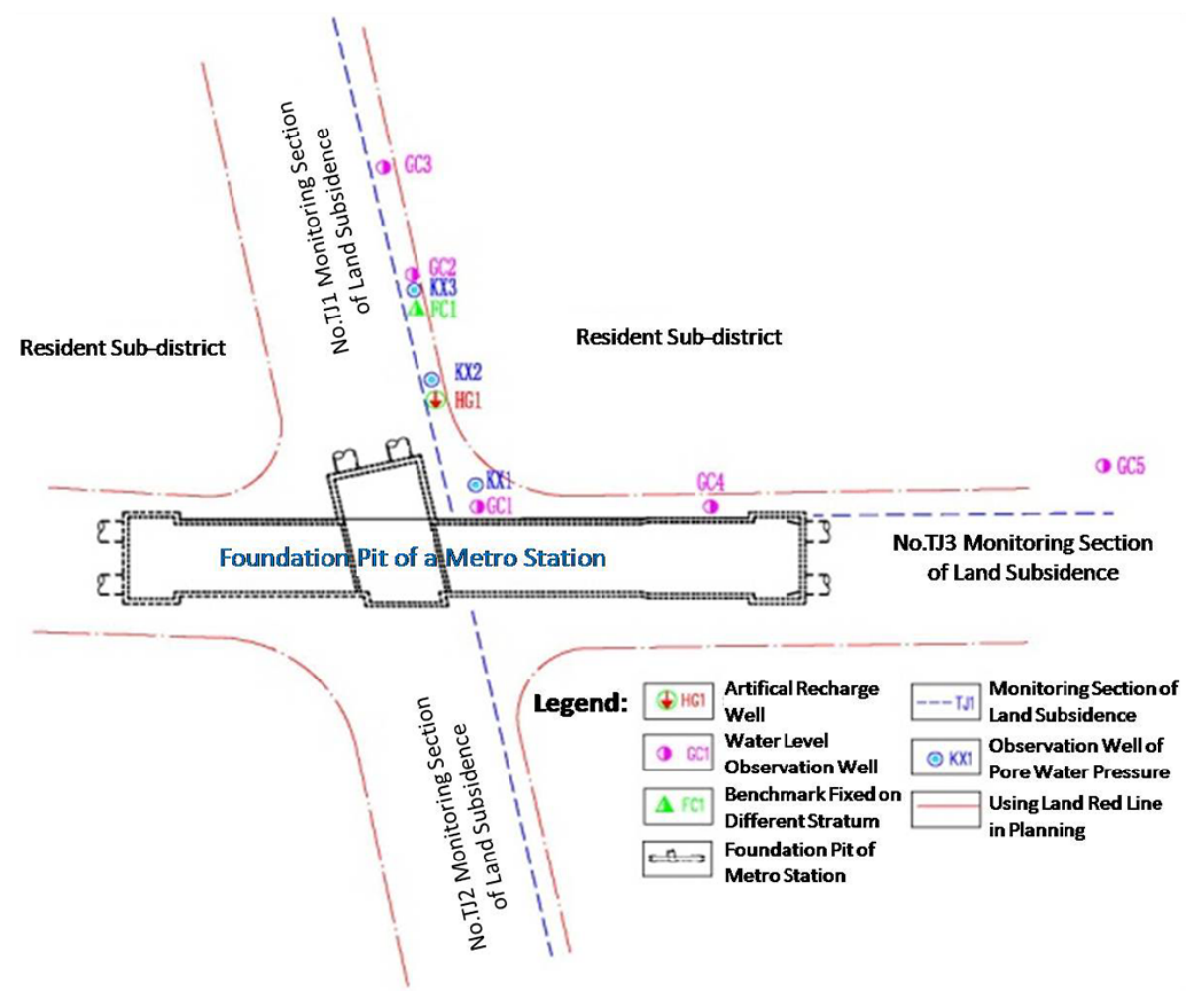

Figure 1. Layout chart of comprehensive testing site of land subsidence control in certain metro station foundation pit.

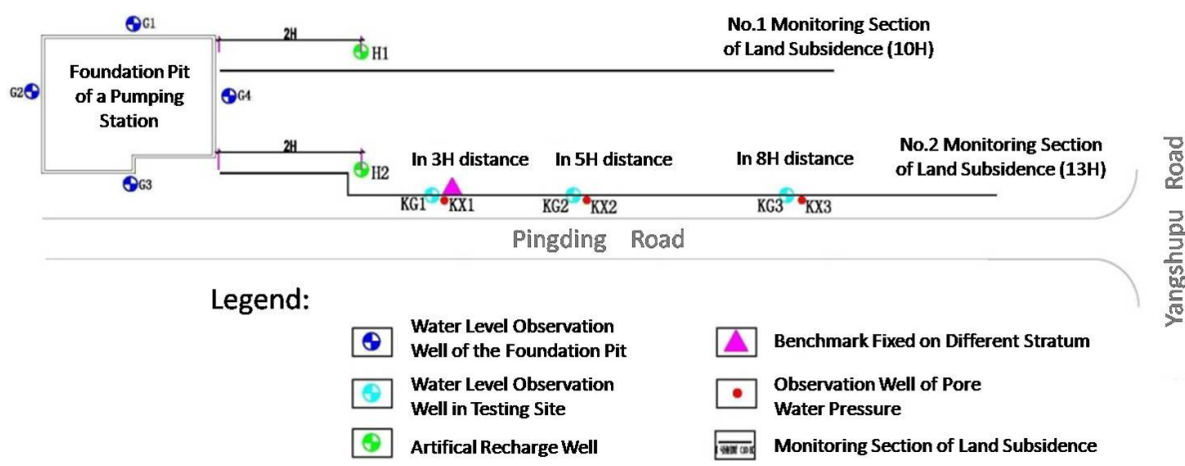

Figure 2. Layout chart of comprehensive testing site of land subsidence control in certain pumping station foundation pit.

\subsection{Construction of the testing site}

To monitor the geological and environmental effects caused by the pit excavation and dewatering, such as land subsidence and groundwater seepage, deep foundation pits of two construction projects in Shanghai were used as comprehensive testing sites to control engineering subsidence. The land subsidence monitoring section, groundwater observation wells for the confined aquifer, pore water pressure monitoring boreholes and extensometers for the layered subsidence of the soil were built inside the influence of the foundation pit and the dewatering (Yang et al., 2010). The length of monitoring section is more than 10 times the excavation depths $(H)$ of the foundation pits. The interval between two monitoring points is 5 to $10 \mathrm{~m}$. Observation wells for the confined aquifer and pore water pressure monitor holes and extensometers (benchmarks fixed on different stratum) for the layered subsidence of soil and recharge wells were arranged in the main monitoring sections of the foundation pits (Wang et al., 2012), shown in Figs. 1 and 2.

\section{Comprehensive test}

According to the test objective and the facilities at the testing sites, the comprehensive test included 2 parts, monitoring and recharge. The monitoring test included the monitoring 


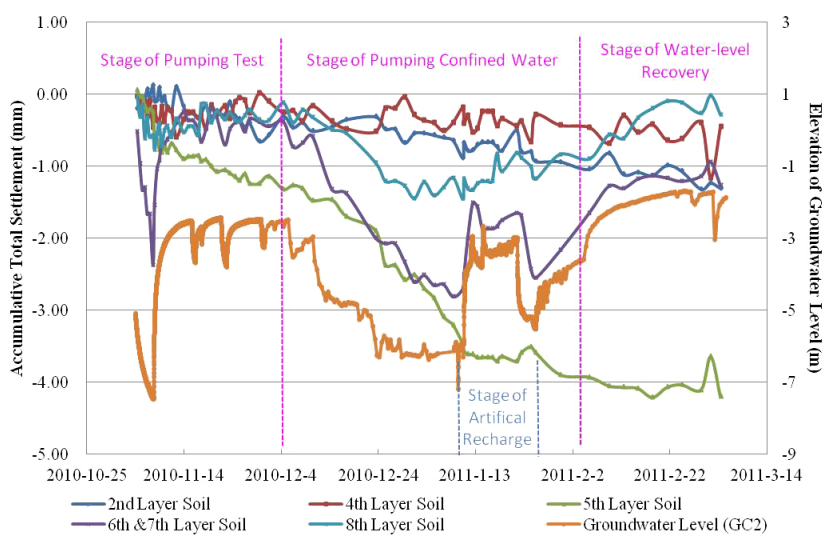

Figure 3. Duration graphical chart of soil laminar settlement and artesian head.

of the water level of the confined aquifer, the layered subsidence of the soil, the pore water pressure and the land subsidence. The monitoring spatial extent (10 times the excavation depth $[H]$ of the foundation pit) covered most of the area influenced by dewatering. Through monitoring the groundwater seepage and the soil settlement during the dewatering period, the relation of the water-level change in the confined aquifer and the land subsidence caused by dewatering of the foundation pit was determined. The recharge test employed an artificial recharge well that penetrated the aquifer targeted for dewatering. A single-well pressurized recharge test was conducted to measure the effect of simultaneously recharging the shallow confined aquifer during the dewatering period on the control of land subsidence.

\section{Comprehensive experimental analysis and study}

The dewatering of the foundation pit during the construction period causes land subsidence in a wide area around the pit. Large scale water level declines in the confined aquifer that may cause environmental problems. About $70 \mathrm{~m}$ from the foundation pit, a group of extensometers, land subsidence monitor section and observation wells for the confined aquifer were set. The relationship between the water level in the confined aquifer and the soil displacement during the dewatering was studied.

\subsection{Characteristics of confined aquifer level and different soil layer subsidence}

A group of extensometers were arranged to measure the layered soil subsidence during the dewatering period. Figures 3 and 4 show the characteristic curves of subsidence of the soil layers. The results indicated that during the excavation and dewatering, with the change of water level, the characteristics of soil displacement were as follow:

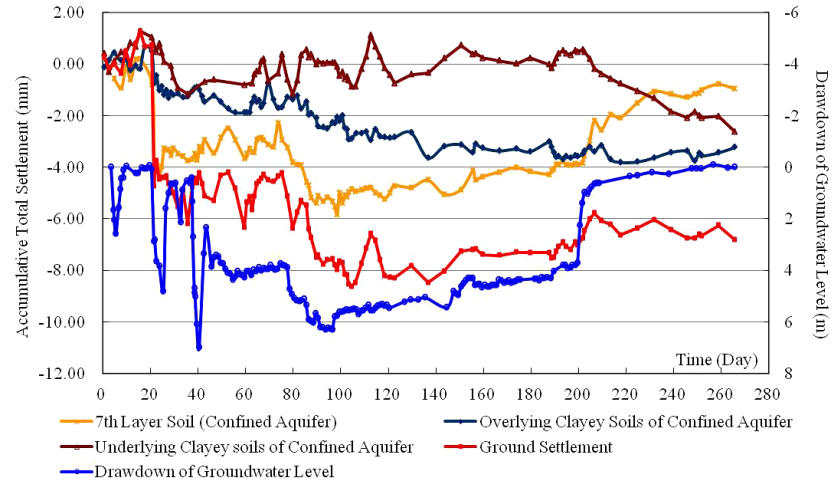

Figure 4. Duration graphical chart of soil laminar settlement and confined aquifer head drop depth at the point of 3 times the depth of foundation pit.

1. During the initial stage of engineered dewatering, with the rapid decline of the confined aquifer water level, compression (settlement) is mainly focused on the soil layer of the confined aquifer. Furthermore, settlement gradually stabilized with stablization of the water level. Following engineered dewatering, the soil layer of the confined aquifer rebounded with recovery of the water level, while the overlying clayey soils sustained compression with gradual slow. At this time, settlement was mainly focused on the overlying clayey soil layer. In addition, during the engineered dewatering, compression of the underlying soil layer of the confined aquifer resulted in small settlement of that layer.

2. From the point of view of deformation characteristic caused by the engineered dewatering, initial settlement mainly showed elastic deformation of the confined aquifer, and overlying clayey soils were less affected. With the increase of pumping quantity and duration, elastic deformation of the confined aquifer was changed into elastic-plastic deformation of overlying clayey soils. After dewatering was over the soil layer of the confined aquifer rebounded, but compression occurred in the overlying clayey soils.

3. A short term of artificial recharge to the first confined aquifer was conducted during the dewatering period. The test result showed that the artificial recharge could increase the confined aquifer water level and reverse settlement of the confined aquifer soil layer, so that the land subsidence could be controlled.

\subsection{Characteristics of confined aquifer level and land subsidence}

Water level in the confined aquifer within the spatial extent of $10 \mathrm{H}$ around the foundation pit varied with distance from the 


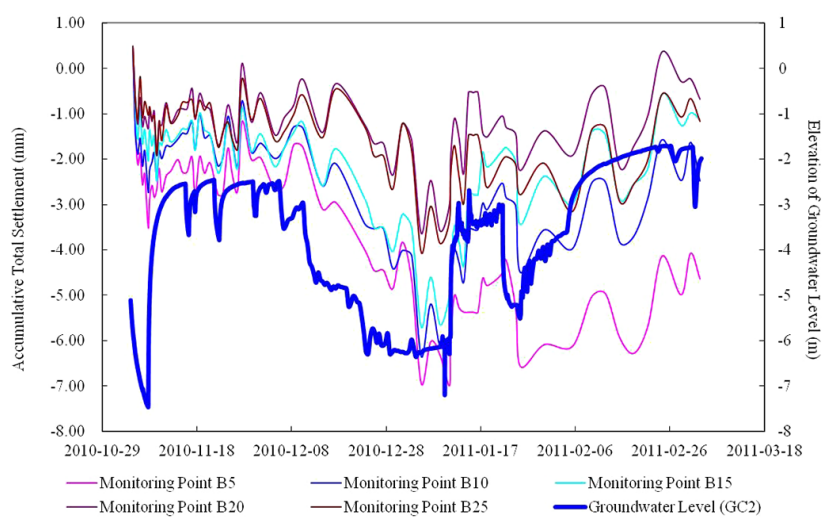

Figure 5. Duration graphical chart of land subsidence and artesian head in monitoring section.

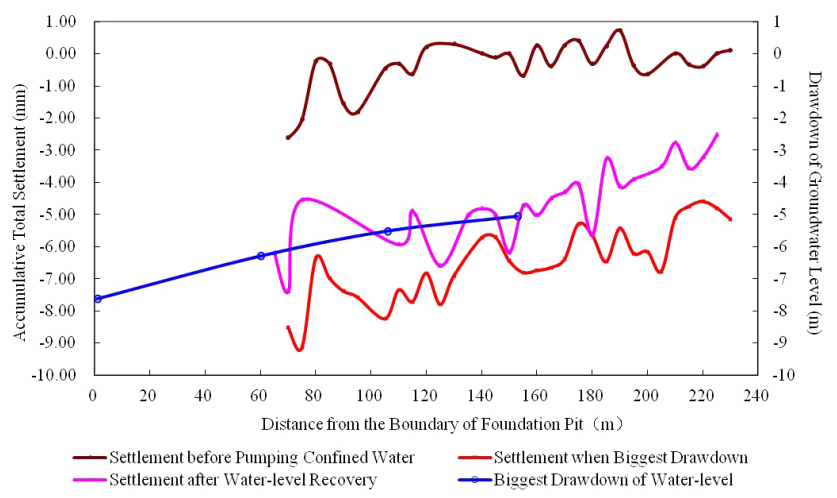

Figure 6. Graphical chart of spatio-temporal features of land subsidence and artesian head in monitoring section.

pit during the excavation and dewatering period. The corresponding subsidence and rebound were monitored. Figures 5 and 6 show the relationship between land subsidence and the water-level change or 3 monitor sections (Fig. 6). The results show the following characteristics:

1. The drawdown and recovery of the confined water level was directly linked with the land subsidence and rebound. The former was the triggering factor and the later the result.

2. The confined water level around the foundation pit dropped a lot during the dewatering period. The spatial extent of the confined aquifer water level influenced by dewatering was larger than $10 \mathrm{H}$, which corresponded with the land subsidence influence. The magnitude of subsidence and the water-level decline gradually decreased with distance from the foundation pit. The subsidence was positively associated with the variation of the confined aquifer water level.

3. The excavation and dewatering were the main reason why land subsidence occurred. Within $3 H$ around the foundation pit, the land subsidence was caused by the

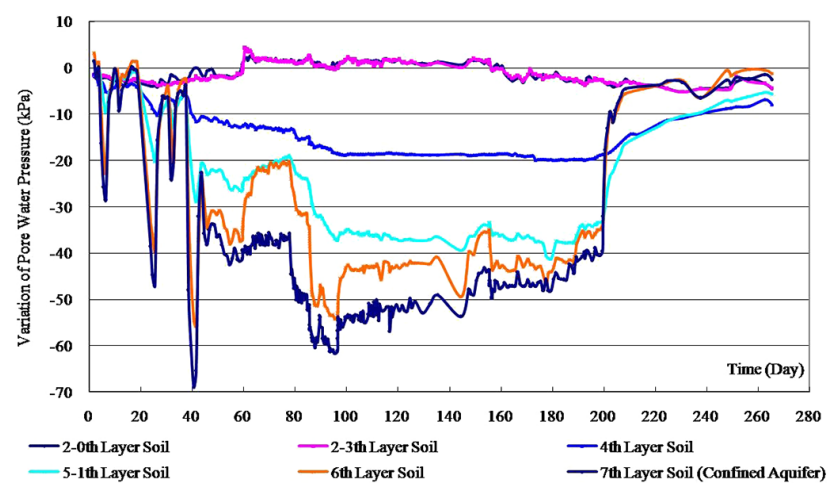

Figure 7. Duration graphical chart of pore water pressure at the point of 3 times the depth of foundation pit.

superposition of excavation and dewatering, and the subsidence magnitude was very large. The subsidence profiles were spoon-shaped. The maximum cumulative subsidence occurred within the site of $0.5-1.0 H$ from the foundation pit. Where the distance was larger than $3 H$ from the foundation pit, the subsidence was caused mainly by dewatering. The subsidence magnitude there was relatively small, yet the scope was very large.

4. A short term of artificial recharge to the objective aquifer was conducted during the excavation and dewatering period. Within the influence range of recharging, soil rebound occurred and the subsidence magnitude was inversely proportion to the distance from the recharge well. So, the simultaneous artificial recharge to the confined aquifer during dewatering could help control land subsidence during the dewatering period.

5. After dewatering, the confined aquifer water level rose, but the subsidence kept developing. When the water level rose for a period of time, the land surface elevation recovered. Within $3 H$ from the foundation pit, the final subsidence magnitude was large while the rebound value was small. Beyond $3 \mathrm{H}$ outside the scope from the foundation pit, the rebound magnitude was large while the final subsidence value was small.

\subsection{Characteristics of pore water-pressure change}

As shown in Fig. 7, during the stage of pumping test and engineered dewatering, the water level (expressed as an equivalent pore water pressure in Fig. 7) in the confined aquifer fell. During this time there was an obvious decline of pore water pressure among the 5th and 6th soil layers overlying the confined aquifer. However, pore water pressure of the 4th soil layer and above was only slightly affected and relatively stable. Following dewatering of the foundation pit ,the water level of the confined aquifer rapidly recovered, but the pore water pressure of the overlying cohesive soil layers recovered slowly. 


\section{Conclusions}

1. The dewatering of foundation pits using hanging waterproof curtains cause land subsidence.

2. The decline and recovery of the confined aquifer water level is directly linked with the land subsidence and rebound. The former is the triggering factor, and the later the result.

3. Monitoring results of extensometers showed that land subsidence caused by dewatering of the foundation pit was mainly comprised of the compression of the targeted aquifer for dewatering - the confined aquifer; and the neighboring soft soil layers. The compression of the confined aquifer was mainly elastic and was in accord with the variation of the confined aquifer water level while the neighboring soft soil layers was visco-elastoplastic and was irreversible.

4. The spatial extent of land subsidence caused by dewatering of the foundation pit using the hanging waterproof curtain was larger than $10 \mathrm{H}$. The magnitude of subsidence and the decline of the confined aquifer water level gradually decreased with the increasing distance from the foundation pit. The subsidence was positively associated with the variation of the water level.

5. Within $3 H$ around the foundation pit, the land subsidence was caused by the superposition of excavation and dewatering, and the subsidence value was large. The subsidence profile was spoon-shaped. The maximum cumulative subsidence occurred within a distance of $0.5-1.0 H$ from the foundation pit. Beyond a distance of $3 \mathrm{H}$ from the foundation pit, the subsidence was caused mainly by the dewatering. The subsidence there was relatively small, yet the spatial extent was large.
6. A short term of artificial recharge to the confined aquifer was conducted during the excavation and dewatering period. Within the range of influence from recharging, soil rebound occurred and the magnitude was inversely proportion to the distance from the recharge well. So, simultaneously, artificially recharging the objective aquifer during its engineered dewatering could help control land subsidence during the dewatering period.

Acknowledgements. This work was supported by public welfare and scientific research subject projects funded by the Ministry of Land and Resources of China (201311045) and major scientific research subjects from the Science and Technology Commission of Shanghai Municipality (12231200700, 14DZ1207802).

\section{References}

Wang, J. X., Wu, Y. B., Zhang, X. S., Liu, Y., Yang, T. L., and Feng, B.: Filed experiments and numerical simulations of confined aquifer response to multi-cycle recharge-recovery process through a well, J. Hydrol., 464-465, 328-343, 2012.

Wei, Z. X., Wang, H. M., Wu, J. Z., Fang, Z. L., and Liu, G. B.: Land subsidence and its influences on urban security of Shanghai, Shanghai Geology, 30, 34-39, 2009.

Yang, T. L.: Analysis of the Land Subsidence Impact of Dewatering of Deep Foundation Pits, Shanghai Geology, 33, 41-44, 2010.

Yang, T. L. and Gong, S. L.: Microscopic analysis of the engineering geologic behavior of soft clay in Shanghai, China, Bull. Eng. Geol. Environ., 69, 607-615, 2010.

Yang, T. L., Yan, X. X., Wang, H. M., Xu, J. H., and Cheng, H. S.: Study on land subsidence induced by excavation engineering, Shanghai Geology, 30, 15-21, 2009.

Yang, T. L., Yan, X. X., Wang, H. M., Wu, J. Z, and Liu, J. B.: Experimental research of shallow aquifer pressure groundwater recharge based on dual control pattern of groundwater level and land subsidence, Shanghai Geology, 31, 12-17, 2010.

Yang, T. L., Wang, H. M., and Jiao, X.: Land subsidence zoning control in Shanghai, Shanghai Geology, 35, 105-109, 2014. 